\begin{tabular}{|c|c|c|c|}
\hline$\Omega$ & [1] & $\equiv$ & (2) \\
\hline $\begin{array}{l}\text { C. Michael Roberts', } \\
\text { Jose Luis Lopez- } \\
\text { Campos }^{2} \text {, } \\
\text { Sylvia Hartl }{ }^{3} \text {, } \\
\text { on behalf of the } \\
\text { European COPD Audit } \\
\text { Steering Committee }\end{array}$ & $\begin{array}{l}\text { 'Barts and The London School of } \\
\text { Medicine and Dentistry, Queen } \\
\text { Mary University of London, } \\
\text { London, UK } \\
{ }^{2} \text { Hospital Universitario Virgen del } \\
\text { Rocí, Instituto de Biomedicina de } \\
\text { Sevilla (IBiS), Seville, Spain } \\
\text { 'Ludwig Boltzmann Institute of } \\
\text { COPD and Respiratory } \\
\text { Epidemiology, Vienna, Austria }\end{array}$ & $\begin{array}{l}\text { C. M. Roberts: Barts and } \\
\text { The London School of } \\
\text { Medicine and Dentistry, } \\
\text { Queen Mary University of } \\
\text { London, London, E12AD, } \\
\text { UK }\end{array}$ & c.m.roberts@qmul.ac.uk \\
\hline
\end{tabular}

\title{
The European COPD Audit: brothers in arms
}

In March 2010, the European Respiratory Society funded a pilot audit programme of the process and outcomes of hospital care for patients admitted with exacerbations of COPD and on the organisation of care at hospital level. Originally it was intended to involve just five countries in this pilot scheme but such was the enthusiasm from national societies that 13 participated in the data collection programme. In March 2012, ERS published a document containing the results at national level for 19,021 cases entered into the audit database and subsequently site specific data has been distributed to each of the 422 hospitals that participated as shown in figure 1 .

These data are unique in that they have been collected by clinicians prospectively identifying cases then recording in hospital care processes and patient outcomes at 90 days after admission date. In order to collect the data, many individuals had to use their time and skills but the success of the data collection is testimony to the enthusiasm of clinicians to better understand the quality of care delivered in their own institutions. The results are salutary and deserve our attention. In essence, they describe a standard of care with significant variation in adherence to guideline standards both within countries and between them. Arterial blood gases are taken on admission in only $12 \%$ cases in one country ranging to $96 \%$ in another whilst antibiotics are given to only $54 \%$ cases in country A yet
$95 \%$ in country B. Unsurprisingly, outcomes vary equally widely with median length of stay at national level varying 5-15 days. At this stage in the data analysis, it is not possible to say why this occurs and there may be a number of explanations. There are certainly significant differences in case mix between countries with, for example, the proportion of male patients ranging $86-47 \%$, the median age of admissions ranging 63-75 years and the proportion of admissions with GOLD stage-IV disease ranging $15-32 \%$ across countries. Some of these case mix differences may reflect the diverse health systems that operate

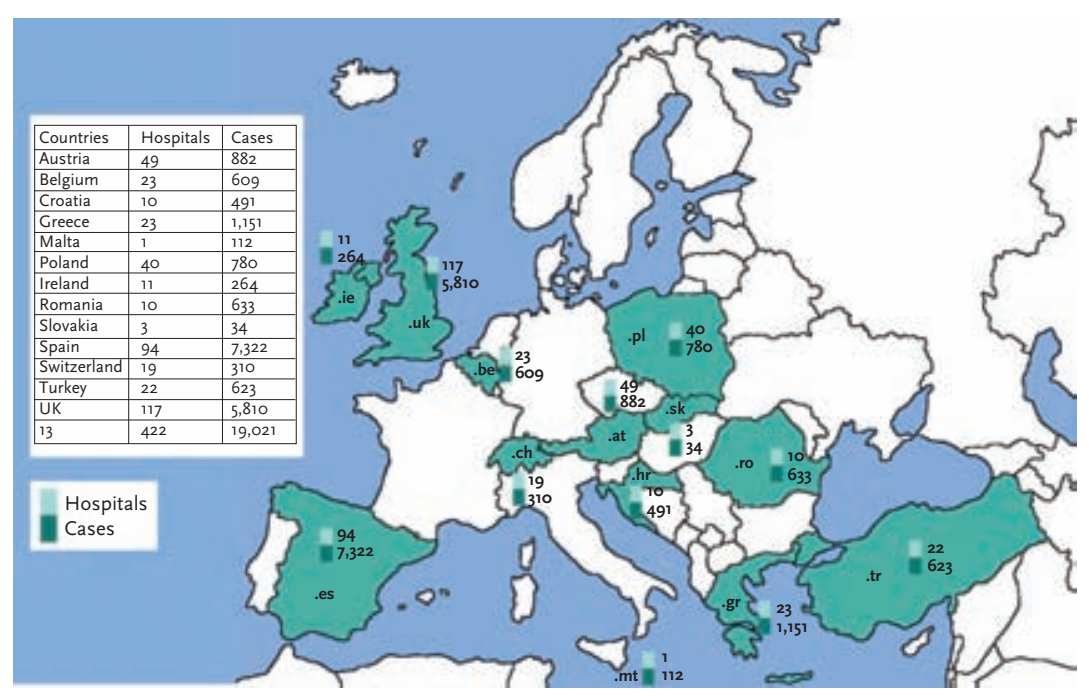

Figure 1

Hospitals participating in the European COPD Audit.
Statement of interest None declared. 
Case collection timeline

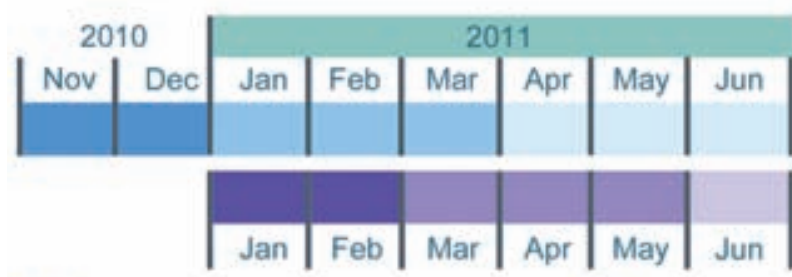

Group 1: inclusion period

Group 1: follow-up period

Group 2: inclusion period

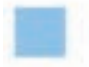

\section{Group 2: follow-up period}

\section{Group 1: data revision}

Group 1: Austria. England, Waies ireiand, Scotiand, Slovakia. Poland

\section{Group 2: data revision}

Group 2. Belgium Greece. Span, Switzeriand Croatia. Romaria Matta. Turkey, Ireland

Figure 2

across Europe and the organisation of care at individual hospital level. The concurrent collection of data on the organisation of care in the same institutions may provide some of the explanations when correlated with observed processes of care. In the same way accounting for case mix variables may help us understand better the variations in outcome observed and how these also relate to process of care. Data from similar audits of COPD care in the UK suggest that case mix and organisational factors account for less than $30 \%$ of the observed variation in outcomes between hospitals [1] and whilst we do not know if this finding will be confirmed within this European study it would not be a huge surprise. It may be the case that some clinical teams do not always deliver the standard of care that is recommended within management guidelines either because their knowledge and application of knowledge are deficient or the care systems that operate within an institution do not support optimum care delivery. In the case of the former it may be for example that an emergency COPD admission comes under the care of a nonrespiratory specialist who may not be wholly familiar with recommended management guidelines or that a doctor who is aware of the appropriate quality standards does not apply them due to other pressures ranging from poor clinical judgment to lack of time. In other cases, the system of care may be inappropriate where patients wait lengthy periods to be seen by a doctor due to inadequate staffing or where specialty care facilities are poor for example a lack of high dependency beds or non-invasive ventilators.

Detailed analysis of the audit data using multi-level multi-variate analysis controlling for clustering is now underway and it is hoped to answer some of these questions soon. Whatever the conclusions drawn, this is not an issue of blame but one of explanation that should help us all understand what affects the delivery of optimum care so that we might all improve our practice.

Whilst these thoughts remain speculative it is imperative that these audit data are not ignored. Audit is far more than a data collection activity. The UK National Institute for Health and Clinical Excellence defines audit as a quality improvement process that seeks to improve patient care and outcomes through systematic review of care against explicit criteria and the implementation of change [2]. In essence, the standards for COPD care are defined by guidelines, whether these are GOLD or ERS/ATS or national documents. The collection of patient data allows us to systematically review the care given against these standards which is the stage of the audit process that the European COPD audit has now arrived at. The next phase however is to identify the deficiencies in care and then implement a change programme of quality improvement to complete the cycle before a further collection of data is made to measure the improvement in care (fig. 2).

So now we have the data and have begun to feed that back to clinicians. Four stages of reaction are described in the recipients of such data:

1. I don't believe the data.

2. I believe the data but the problem isn't mine.

3. I believe the data and understand it's my problem but don't know how to fix it.

4. I understand the problem and have a plan to fix it.

Wherever we stand within those stages we all have a responsibility to reflect on the data to better understand how we may all improve the care delivered to our patients.

In order for us to move toward stage 4, we need to engage our colleagues, clinicians and managers with the audit data and with suggestions on how to improve the quality of the care we deliver. Some of that information will come out of the further analysis of the audit data sets where organisation and resources will be correlated with process achievements and better outcomes for patients. We must not however underestimate the barriers 


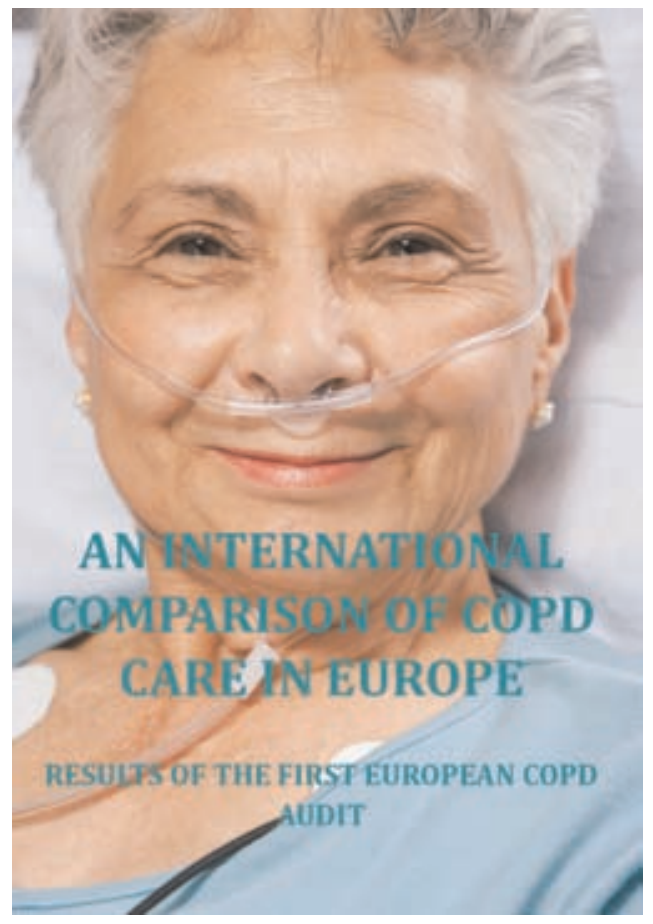

to change [3]. Many clinicians face difficulties with a lack of personal time to devote to audit, a reluctance to invest in change enhanced by a perception that control is in the hands of others and, lastly, in some cases, a lack of necessary personal skills that results in demotivation. To overcome these issues is no mean feat but it is possible with the aid of audit data. Deficiencies in care can be analysed so that education and training needs may be met. Organisation of care can be addressed by clinical teams and managers working with the same aims informed by the data and the power of a clinical champion who can motivate others should not be underestimated. Innovative service improvements can save money as well as patients and are a motivation to engage managers and funders working with clinicians. We can also learn from other areas of medical practice where the "care bundle" concept has provided a mechanism with which to drive important care quality improvements notably in intensive care [4] and infection control [5] and now recently adopted in COPD [6].

What is clear already is that some of the participating hospitals have already engaged in innovative care pathways for patients that, if shared, could be adopted more widely. The richness and diversity of the European healthcare systems is a huge strength of ERS. Yet, whilst these different systems have developed to meet the needs of local populations and social networks, the guidelines are international, and research-based evidence and expert consensus are equally applicable to all people with COPD regardless of their chance place of birth. Within this range of systems it would seem logical to consider what best works for COPD patients and to consider adopting that system of care more widely across Europe rather than retaining isolated pockets of excellence. With this in mind the European COPD steering committee is seeking funding to hold a series of quality improvement meetings across Europe in 2012/2013. The aim of these meetings will be to facilitate clinicians and managers of healthcare to move around the audit cycle to plan and implement the necessary changes at both local and, where relevant, national level. Hospital teams which have demonstrated innovative and successful COPD programmes will be invited to share their expertise across a wide European audience. Identification of area of deficient care within the COPD patient pathway will provide opportunities for the ERS and the ERS School to provide education and training support to address these specific issues. Good practice and the demonstration through data analysis of correlates with better patient outcomes may inform future COPD guideline recommendations.

ERS has used the data to engage members of the European Parliament in discussions around further smoking restrictions and the formulation of a strategy for non-infectious chronic respiratory diseases. National societies have their own data to compare with the European results and should use these to argue for better service organisation and resources at local and national level. We as participant clinicians should share our data with hospital clinical teams and managers both within and outside the respiratory community to seek service improvements based on factual data. In time, the steering group hopes to make the audit tool available to a wider group of hospitals across more countries and is actively seeking funding for this proposal.

It would seem unlikely that any doctor caring for COPD patients wishes to do less than their best for the patient, yet there is observed significant variability in the care delivered across Europe now. The first step for us as individuals and as organisations is to reflect on the data on the standard of care delivered. Without receiving this feedback it is 
Visit the COPD Audit website for more details: www.erscopdaudit.org difficult for any of us to understand where our real strengths and weaknesses lie. Having done this, we need to work with the whole care team and managers to plan effective change and implement them. A number of other European societies have begun audit pilots [7, 8] but few have since published data with only expressed aspirations to establish a quality improvement programme. We are now brothers in arms in the fight to provide best care for our patients. The COPD audit programme has provided the data ammunition to inform the quality improvement agenda. We must now use these data to plan an improvement programme for our services at local and national level and then implement those changes leading from the front.

The time is right for the European respiratory community to take a lead in this critical area of medical practice for the benefit of our patients and for our own professional satisfaction. Let us not lose the moment!

\section{References}

1. Price L, Lowe D, Anstey K, et al. The UK national COPD audit 2003. Impact of hospital resources and organisation of care on patient outcome following admission for acute COPD exacerbation. Thorax 2006 61: 837-842.

2. NICE Best clinical practice audit 2002. www.nice.org uk/media/796/23/BestPracticeClinicalAudit.pdf Date last accessed: March 5, 2012.

3. NICE How to guide change practice 2007. www.nice.org uk/media/AF1/73/HowToGuideChangePractice.pdf Date last accessed: March 5, 2012.

4. Ferrer R, Artigas A, Levy MM, et al. Improvement in process of care and outcome after a multicenter severe sepsis educational program in Spain. JAMA 2008; 299: 2294-2303.
5. Aboelela SW, Stone PW, Larson EL. Effectiveness of bundled behavioural interventions to control healthcare-associated infections: a systematic review of the literature. J Hosp $\ln f$ 2007; 62: 101-108.

6. Hopkinson NS, Englebretsen C, Cooley N, et al. Designing and implementing a COPD discharge care bundle. Thorax 2012; 67: 90-92.

7. Escardio CARDS dataset. www.escardio.org/Policy/ Documents/CARDS-dataset-PCl-1104.pdf Date last updated: November, 2004; Date last accessed: March 5, 2012.

8. European Society Radiology (ESR) European Commission guidelines on clinical audit. Statement by the European Society of Radiology. Insight Imag 2011; 2: $97-98$. 